\title{
Assessment of Internal Control Systems of Technical Universities in Ghana
}

\author{
Dorcas Otengkoramah Badoo*, Hilda Hammond, Felix Oppong
}

Finance Directorate, Accra Technical University, Accra, Ghana

Email address:

otengkoramabadoo@yahoo.co.uk (D. O. Badoo)

${ }^{*}$ Corresponding author

\section{To cite this article:}

Dorcas Otengkoramah Badoo, Hilda Hammond, Felix Oppong. Assessment of Internal Control Systems of Technical Universities in Ghana. Journal of Finance and Accounting. Vol. 8, No. 2, 2020, pp. 64-72. doi: 10.11648/j.jfa.20200802.12

Received: March 18, 2020; Accepted: April 1, 2020; Published: April 13, 2020

\begin{abstract}
The relevance of internal control systems in organizations have been duly recognized as a process for assuring the achievement of set objectives in operational efficiency, reliable financial reporting and compliance with regulatory and international standards. For Technical Universities (formerly, the Polytechnics), as public institutions with the attendant problem of limited resources, it is imperative to implement effective internal controls for the judicious utilization, monitoring and management of business processes towards success and sustainability. The study, sets out to assess internal control systems at Accra Technical University, investigating the existence and implementation effectiveness and related challenges of such internal controls. The specific objectives were to find out the internal control systems at Accra Technical University, the extent of employee awareness of the control systems, consistency of the control systems with national and international standards, and the effective implementation of the control systems. The study used both primary and secondary data sources. The primary data was collected with a questionnaire from respondents comprising mainly staff from the Finance, Audit, Administration and Academic departments while secondary data was gathered from review of documentation at the Finance Office. The study reveals that Accra Technical University has instituted policies and procedures to enhance the implementation of internal controls, however, there is low staff awareness regarding such policies and violation penalties. This, it is noted, stems from Management's inability to communicate information regarding internal control policies to staff promptly and effectively. Further, Accra Technical University exhibits high conformity to international standards and the present national regulatory regime in the preparation of its financial reports and fiscal management. Overall, the implementation of internal control systems at Accra Technical University is rated as "quite effective" and directed mainly towards conducting business in an efficient manner and ensuring financial information are accurate and complete. It is recommended, therefore, that Management improves staff awareness of policies regarding internal controls, and undertake continuous monitoring, identification and assessment of the internal control systems established and implemented to ensure they are functioning properly and meeting expectation.
\end{abstract}

Keywords: Internal Controls, Financial Reporting, Staff Awareness

\section{Introduction}

\subsection{Background to the Study}

The importance of internal controls in the day to day activities of individuals and organizations cannot go unnoticed. Internal control as defined in accounting and auditing, is a process for assuring achievement of an organization's objectives in operational effectiveness and efficiency, reliable financial reporting and compliance with regulations and policies. In a broad concept, internal control involves everything that controls risk to an organization. It is a means by which an organization's resources are directed, monitored, and measured. It plays an important role in detecting and preventing fraud and protecting the organization's resources, both physical and intangible as in [1]

An internal control system consist of all the policies and procedures adopted by the directors and management of an entity to assist in achieving their objective of ensuring, as far as practicable, the orderly and efficient conduct of its business, including adherence to internal policies, the 
safeguarding of assets, the prevention of fraud and error, accuracy and completeness of the accounting records and the timely preparation of reliable financial information. Internal control systems extend beyond those matters which relate to the accounting system.

The International Accounting Standard 400 risk assessment and internal control defines two elements in controls, The Control Environment and the Control Procedures. The control environment is the framework within which controls operate. The control environment is very much determined by the management of a business. The Control environment is the overall attitude, awareness and actions of director's managers regarding internal controls and their importance in the entity. Control procedures on the other hand, are the rules, regulations, processes, documents, policies and principles management has instituted in the organization to ensure that the controls work effectively or are duly followed in the organization.

Technical Universities in Ghana face a lot of challenges in the management of its limited resources and meeting of their objectives, and as such require effective internal control systems to provide some level of assurance of efficiency and effectiveness in the use of its resources even though humans can limit the effectiveness of internal controls. The Technical University Act, 2016 (Act 922) came into force in 2016 to convert qualified polytechnics in Ghana to Technical Universities to provide higher education in engineering, science and technology based disciplines, technical and vocational education and training, applied arts and related disciplines.

The Technical Universities are governed by the Technical University Act, 2016 (Act 922), the respective Technical Statutes and the Constitution of the Republic of Ghana. As public sector institutions, it is mandatory for the Technical university to comply with the provisions, laws and regulations such as the Public Financial Management Act, 2016, Public Procurement Act, 2016 (Act 914), Financial Administration Regulation, 2004 (L. I. 1802), Internal Audit Agency Act, 2003 (Act 658), Audit service Act, 2000 (Act 584), and the Labour Act, 2003 (Act 651).

Internal controls plays a vital role in ensuring accurate reports, safeguarding of tangible and intangible assets of an organization and elimination of fraud and errors. Iddrisu and Anang [2] advised that judicious financial management do not apply to only governmental institutions or the financial institutions but also applies to every facet of the economy which does not exclude the education sector.

At one of the internal audit forum organized by the Internal Audit Agency (IAA), in Accra under the theme: "Mitigating corporate fraud, abuse and waste: the role of the internal auditor" [3], the President of Ghana in the year 2007 urged all public sector Chief Executives to develop and make operational effective internal controls in a speech read on his behalf by the Minister of Finance and Economic Planning. He added that domestic, international fraud and economic crime pose a threat and has a link with terrorism, poverty and drugs as reported by [3]. From the above it is therefore important to say that Internal Controls play a significant role in helping an organization achieve its goals, thus, the need for this study to assess the internal control systems of the Technical Universities, a case study of Accra Technical University.

\subsection{Statement of Problem}

Internal Control is an integral part of an organization's governance system and ability to manage risk, which is understood, effected and actively monitored by the governing body, management, and other personnel to take advantage of the opportunities and to counter the threats in achieving the organizations' objectives. Internal Control is affected by people. It is not merely policy manuals and forms, but people functioning at various levels of the institution. It provides reasonable assurance to an institution's leader regarding achievement of operational, financial reporting and compliance objectives.

Everyone therefore has a part to play in the internal control system. The roles vary depending upon the level of responsibility and nature of involvement by the individual. The Vice Chancellor establish the presence of integrity, ethics, competence and a positive control environment. The Deans, Directors, Heads of Departments and Sectional Heads have oversight responsibilities for internal controls within their areas. Managers and supervisors are responsible for ensuring that internal controls are established and functioning to achieve the mission and objectives of their units. Each employee within a division must be made aware of and understand internal control procedures associated with their specific function. Thus, the study on the assessment of internal control systems at the Technical University.

\subsection{Research Objectives}

The main objective of the study is to assess the existence, implementation and effectiveness of internal control systems at Accra Technical University. Specifically, the study aims to;

1) Identify the internal control systems and employee awareness at Accra Technical University;

2) Ascertain compliance of the internal control systems at Accra Technical University with International Standards;

3) Determine and assess the control procedures instituted in furtherance of internal control systems at Accra Technical University;

4) Assess how the control environment affects implementation of internal controls at Accra Technical University;

5) Identify implementation challenges of internal controls at Accra Technical University and make appropriate recommendations for managerial consideration.

\subsection{Significance of the Study}

At the point of attaining organizational objectives and to create, enhance and protect stakeholder value is the ability to effectively manage risk, making internal control an 
indispensable aspect of the governance structure of organizations. High-profile organizational failures typically lead to the imposition of additional rules and requirements, as well as subsequent time-consuming and costly compliance efforts. The right kind of internal controls will enable an organization to take advantage of opportunities while offsetting threats and this can save time, money, and promote the creation and preservation of value. Effective internal control also creates a competitive advantage, as an organization with effective controls can take on additional risk.

In addition to assisting management in effectively carrying out its responsibilities, Internal Controls also help external auditors in reducing their audit work and subsequently, save on time and costs. Internal control systems allow the auditor to reduce the need for routine, mechanical verification of bookkeeping accuracy, permitting substitution of less time consuming approach that involves reasoning, judgment and stress such activities as reviews, analysis evaluation and statistical sampling.

Technical Universities like all other institutions have very limited resources as funding from the government comes in late or not at all, thus much pressure is put on the funds generated internally. These funds must be used effectively and efficiently to yield maximum benefit in fulfilling the goals and objectives of the Technical University.

Accra Technical University aims at preparing career graduates who combine theory with practical competence. In view of this, the institution has over the years excelled in providing career-focused and community based education which is developed in partnership with employers. This places the University far ahead of other analogous institutions in the country.

The study would assist management to strengthen its control systems through highlighting the weaknesses of the existing systems and possibly, adopt some of the recommendations which will enhance their control, monitoring function and financial planning in achieving its goals and objectives with their limited resources. With employees sensitized on the importance of Internal Control System (ICS), all will appreciate the importance of ICS's, resulting in effective communication and enhance the smooth flow of work.

\section{Methodology}

\subsection{Research Design}

Yin defines case study as an empirical study that "investigates a contemporary phenomenon (the case) in depth and within its real-life context especially when the boundaries between phenomenon and context are not clearly evident" [4]. This is consistent with Baxter and Jack's assertion that the case study approach explores a phenomenon within its context [5]. Further, they note that this in-depth investigation of the case is enhanced by the use of multiple sources of evidence, allowed in the case study approach reported in [5]. The study sought to access the internal control systems at Accra Technical University. The case study approach has been adopted as it permits a holistic study of an entity (the case) and enables a detailed investigation of the phenomenon of internal controls. This fits the present study with an overarching aim to assess internal controls at Accra Technical University in detail to provide new insights and a depth of information pertaining to the University's implementation of internal controls. Further, the exploratory single case study carried out by [4], was adopted since Accra Technical University is representative of the situation in the other Technical Universities in Ghana and is appropriate to reveal the existence and effectiveness of internal controls in the Technical Universities.

The two main categories of methodological approaches used are the qualitative and quantitative methods. The qualitative method is often descriptive compared to the more statistically based quantitative method leading to inferences on the larger population. Noting that the core of the study is not merely to generalize but assess internal controls in Accra Technical University, the case study design and underlying qualitative methodological approach was adopted. Although the case study itself may not ensure generalization, this choice establishes a basis to apply the findings of the present study and extend the method in similar studies [6].

As noted by [5], a key strength of case study approach is the use of multiple data sources including archival records, documentation, interviews, direct observation, and participant observation etc. The approach adopted by the study allowed the use of multiple data sources - direct responses through questionnaire and document analysis - to elicit and gather adequate information to answer research questions raised in the study.

\subsection{Population and Sampling}

The case site is Accra Technical University which makes all staff the population for the study. However, in order to properly evaluate and draw reasonable conclusion, the study chose a purposive target sample of staff in the Finance, Audit and related offices and functions.

\subsection{Data Collection and Instrument}

The study used data from both primary and secondary sources. Questionnaire was used to elicit information from staff in the selected departments forming the primary data source whereas review of documents pertaining to statutory regulations and financial standards formed the secondary data. The measures for the questionnaire were adopted for the current study from reviewed literature, making their validity and reliability tested and proven.

\subsection{Framework of Data Analysis}

The data collected from respondents were coded and analyzed using Statistical Package for the Social Science (SPSS) with appropriate charts and tables to answer the questions posed in the study and to draw relevant conclusions. 
The focus of qualitative studies is contextualization, investigating a phenomenon in detail to understand people, groups or organization and the situation in which they act as indicated in [7]. The data analysis used descriptive statistics of tables and charts to bring order, structure and interpretation to the data collected. The essence is more on identifying new insights and implementation challenges mitigating against the effectiveness of internal controls at Accra Technical University

\section{Results and Discussion}

The thrust of this study is to assess the internal control systems at Accra Technical University. The study sought to answer the following research questions:

1. The internal control systems at Accra Technical University.

2. Employees awareness of the internal control systems at the University

3. Control systems consistent with internationally acclaimed standards, example by Internal control systems having a bearing on Financial Administration Regulation, 2004 (L. I. 1802), Public Procurement Act, 2003 (Act 663), Internal Audit Agency Act, 2003 (Act 658), Audit service Act, 2000 (Act 584), and the Labour Act, 2003 (Act 651)?
4. How the control environment within Accra Technical University favour the effective implementation of the internal control systems.

5. Control procedures instituted by the University's Council and Management for the effective implementation of internal control systems.

\subsection{Participant Characteristics}

As indicated in table 1 , a total of 18 respondents drawn from the departments of finance with its accounts, payroll sub-sections, internal audit, general administration and academic department, that is math and statistics departments comprised $61.11 \%$ of males and $38.89 \%$ of females. Collectively, there were $55.56 \%$ senior staff, $38.89 \%$ senior members and only $5.56 \%$ junior staff. The survey showed that $(33.33 \%)$ of the staff have worked (served) between 1-5 years, $(44.44 \%)$, between $6-15$ years and $(22.22 \%)$ above 15 years with no respondents serving below 1 year. Overall, the highest educational qualification of most respondents is Bachelor's degree (50.00\%), followed by Master's (33.33\%) and professional certifications $(16.67 \%)$. The characteristics of the respondents are diverse and appropriate to provide information representative of the study population necessary to undertake a proper assessment and evaluation of internal controls at the University.

Table 1 Respondent Characteristics.

\begin{tabular}{|c|c|c|c|c|c|}
\hline & Count & Percent & Education & Count & Percent \\
\hline \multicolumn{6}{|l|}{ Gender } \\
\hline Male & 11 & 61.11 & Secondary & 0 & 0.00 \\
\hline \multirow[t]{3}{*}{ Female } & 7 & 38.89 & Diploma & 0 & 0.00 \\
\hline & 18 & 100.00 & Bachelor & 9 & 50.00 \\
\hline & & & Masters & 6 & 33.33 \\
\hline Staff Category & & & $\mathrm{PhD}$ & 0 & 0.00 \\
\hline Junior Staff & 1 & 5.56 & Professional & 3 & 16.67 \\
\hline Senior Staff & 10 & 55.56 & Other & 0 & 0.00 \\
\hline Senior Member & 7 & 38.89 & & 18 & 100.00 \\
\hline \multirow[t]{2}{*}{ Total } & 18 & 100.00 & & & \\
\hline & & & Department & & \\
\hline Years Served & & & Finance & 8 & 44.44 \\
\hline Below 1 year & 0 & 0.00 & Accounts & 1 & 5.56 \\
\hline $1-5$ years & 6 & 33.33 & Payroll & 1 & 5.56 \\
\hline $6-15$ years & 8 & 44.44 & Internal Audit & 6 & 33.33 \\
\hline Above 15 years & 4 & 22.22 & Administration & 1 & 5.56 \\
\hline \multirow{2}{*}{ Total } & 18 & 100.00 & Maths and Stats & 1 & 5.56 \\
\hline & & & Total & 18 & 100.00 \\
\hline
\end{tabular}

\subsection{Analysis of Responses}

\subsubsection{Control Systems Available at Accra Technical University}

The results indicate that control systems in the following areas are present at the University:

1. Conducting business in an orderly and efficient manner

2. Accuracy and completeness of financial information

3. Adherence to internal controls

4. Prevention and detection of fraud and errors
5. Safeguard assets

As indicated in figure 1 below, the control systems at Accra Technical University are consistent with [8], definition of internal control mainly as a tool to promote operational efficiency and Committee of Sponsoring Organizations [1], assertion that internal controls play critical role in protecting organization resources as well as preventing and detecting fraud. This is noteworthy in the efforts of the University to harness its key strengths and mitigate weaknesses to deliver on their mission and goals for organizational success. 


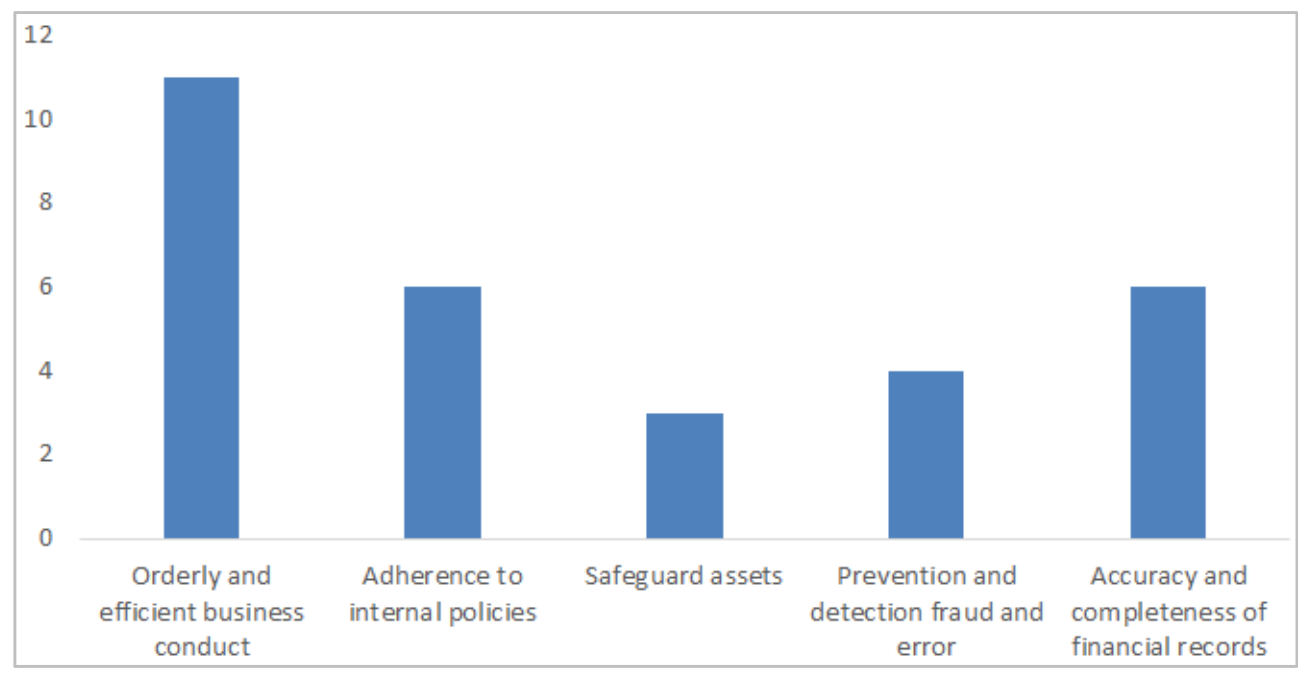

Figure 1. Internal Control Systems at Accra Technical University.

\subsubsection{Employee Awareness of Internal Controls at Accra Technical University}

To ascertain the level of staff awareness of the existence of internal control systems at the University, the results reveal the following (see figure 2):

1. Employees/staff of Accra Technical University were split on their agreement and disagreement on the existence of well documented structures and code of practice for all.
2. Similarly, just about half the employees/staff acknowledge they were aware of policies and procedures regarding internal controls established in the University.

3. Intriguingly, while majority of respondents contend staff are not aware of penalties for breaching internal control procedures, a good number of respondents were not sure and cannot categorically place staff awareness.

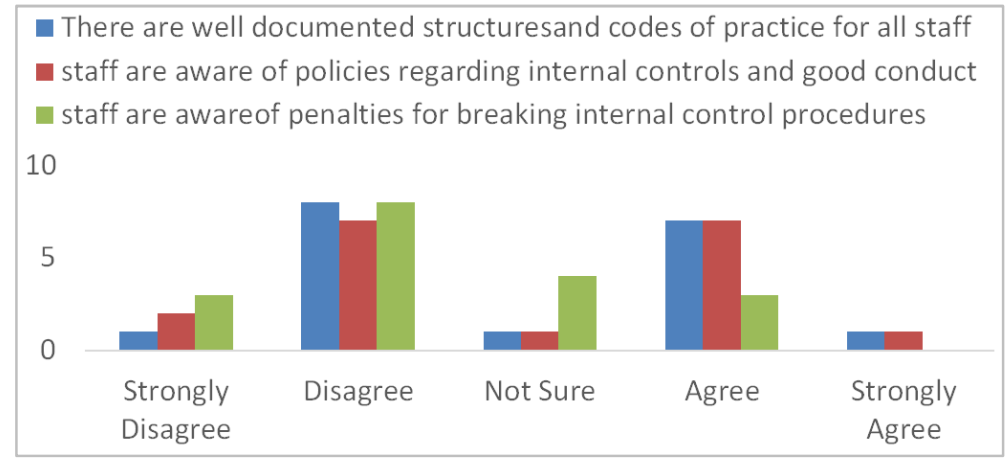

Figure 2. Staff Awareness of internal Control Systems.

Overall, there were mixed indication of staff awareness about internal control systems and related policies and procedures at the University. It was not clear whether or not appropriate documents exist and made available to employee/staff accordingly. To effectively implement internal controls, the staff cannot be left out. As noted by Corbetta and Salvato [9], the stewardship theory, a complement to agency theory posits the co-existence of non-economic, trust-based relationships alongside agency relations in organizations, arising from the principal-agent interest convergence. It is imperative to attain a shared set of values exhibited by the principal (management) and the agent (staff), [10-11]. This does not augur well and should be treated by promoting awareness of internal control mechanisms and policies throughout the organization

\subsubsection{Consistency of Control Systems with International Accounting Standards}

As depicted in figure 3 below, result suggest that the preparation of financial records and information are consistent on the basis of prescribed standards and meets statutory regulations. Also, there is an independent audit committee, but their existence is not enough proof that they carry out their prescribed activities efficiently and act with independence. Although effective control environment exist, there is doubt if it is sufficient to address control activities. However, there is an effective organization structure that shows lines of authority. Management is noted to undertake reviews of control activities, this is not as regular and frequent as should be the case in line with best practices. Not least, the posture of the internal audit department portrays 
independence, yet, there is still doubt if in reality, the division act with independence from Management.

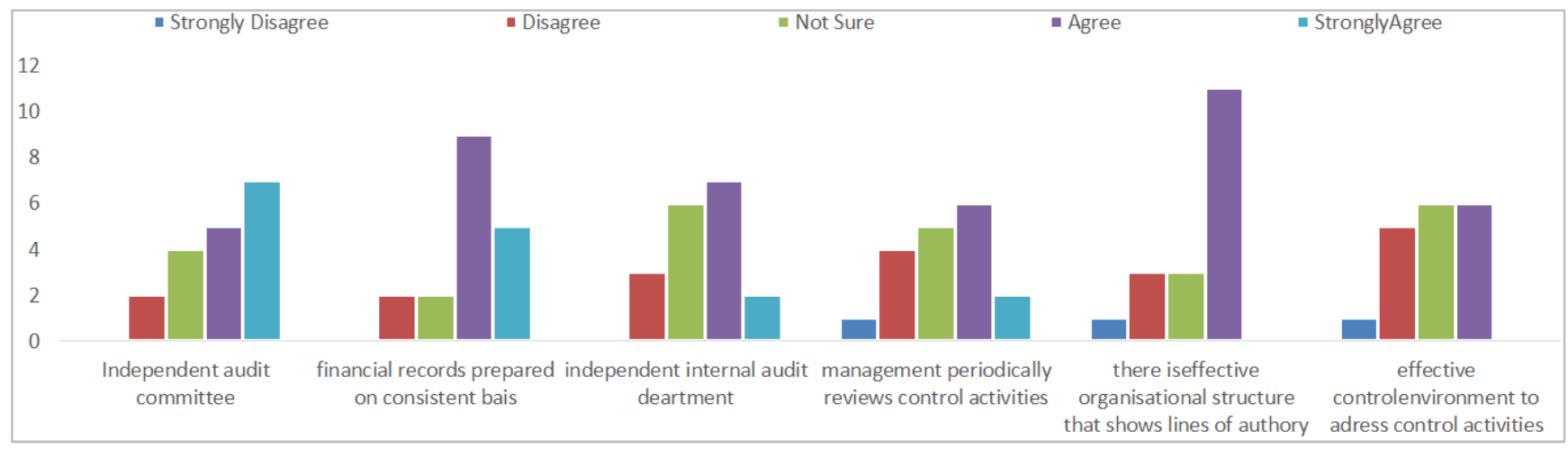

Figure 3. Compliance of internal Control Systems at Accra Technical University.

Further, [12], Framework and Sarbanes Oxley Act (SOX) Compliance present 17 internal control principles to be complied with. The study reveals that Accra Technical University complies with some of these guidelines by practicing the following:

Management demonstrates commitment to integrity and ethical values and exercise oversight responsibility; establishing structure, authority and responsibility.

Management demonstrates commitment to competence and enforces accountability.

The University undertakes risk assessment, selects and develops control activities, deploys policies and procedure geared towards mitigating fraud and error.

The Technical University uses relevant information in communicating internally and externally.

\subsubsection{Influence of Internal Controls on National Regulatory Framework}

Accra Technical University's internal control system is more effective due to the religious use and adherence to the provision of Financial Administration Regulation and Act [13, 14]. On page 11 of the Regulation is the accounting manual prepared by the Controller and Accountant-General from which Departmental Accounting Instructions are derived. The Departmental Accounting Instructions indicate that "a head of department shall with the approval of the Controller and Accountant-General given in consultation with the Auditor-General issue Departmental Accounting Instructions to regulate the financial business of the department, indicating the duties to be performed by specified officers [13].

Financial discipline [13] is practiced by the Technical University and this has impacted the Technical Universities control system positively.

Instructions contained in these Regulations or Accounting Instructions for which no variation is permissible, in any circumstances whatsoever, shall be deemed to include a provision that any contravention will amount to breach of financial discipline.

Any person required to perform any function or duty under the Act or under these Regulations who fails to perform that function or duty within the time required, is in breach of financial discipline under the regulation.

Disciplinary action for misconduct shall be taken by the head of department against any officer contravening any instruction specified, in accordance with these Regulations.

Sanctions for breach of financial discipline shall include reprimand, suspension, demotion, interdiction and termination.

Failure by a head of department to take disciplinary action where required under this regulation shall itself be a breach of discipline under this regulation.

More so, Accra Technical University uses the Labour Act [15] in the management of its Human Resource. Part III of the Labour Act section 8 to 15 is continuously used by the University. For control purposes, the Technical University has adopted Schedule 1 of section 13 [15] a "written statement of particulars of contract of employment". The Internal Audit Agency Act, [16] requires that there shall be established in each Ministry Department and Agency an Internal Audit Unit. The Technical University has complied with this Act wholly by establishing an Internal Audit Directorate that uses both the Audit Service Act [17] and [18] in the discharge of its duties. The Internal Audit Office at Accra Technical University exhibits professionalism and competence by maintaining integrity and confidentiality stipulated by the Internal Audit Agency Act.

The overall objective of the Public Procurement system is to provide value for money to the Government by ensuring that public funds are spent in a transparent, efficient and fair manner. This Manual incorporates policy provisions and procedures to promote transparency, accountability and ethics in the operation, management and reporting of procurement and asset disposal. All Public Servants shall consistently apply these policies and procedures, together with professional judgment and good management, [18]. This has a great impact on internal control system of an institution as any officer who flouts these principles are sanction by the government. The University uses the Procurement Act judiciously in the transacting of its activities.

\subsubsection{Policies and Procedures Instituted for the Effective Implementation of Internal Controls}

The study assessed a total of ten (10) policies and 
procedures at the Technical Universities. Results are depicted in figure 4 below. To ascertain the presence or otherwise of these policies and procedures, the study averaged the response scores for each item. A mid-point of 3 indicates respondent neutrality (not sure) of presence of the policy or procedure; average scores of below 3 indicate the policy or procedure is not present (combined strongly disagree and disagree ratings) whiles an average score of above 3 indicates the policy or procedure is present (combined strongly agree and agree ratings).

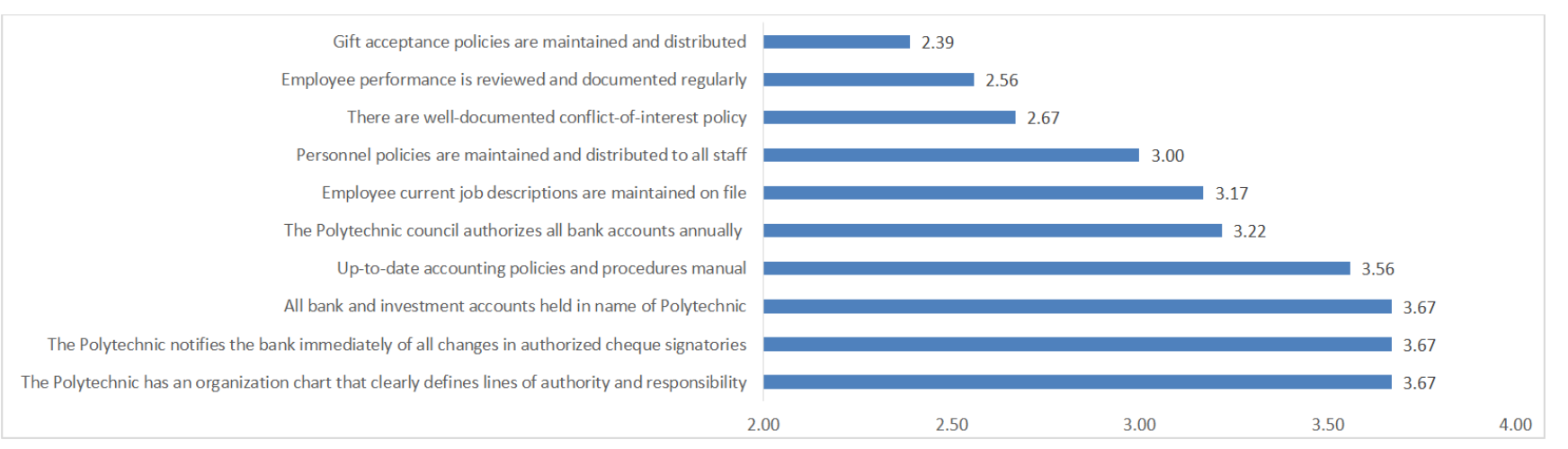

Figure 4. Policies and procedures instituted at Accra Technical University.

Results indicate that, although they exist, respondents are not certain about the effectiveness of personnel policies. Further, respondents disagree to the existence of gift acceptance policies; employee performance reviews and documentation as well as the existence of well documented conflict-of-interest policies. However, they acknowledge the existence of job descriptions for each employee, bank account authorization by council, and up-to-date accounting policies and procedures manual. Moreover, they note that bank investments and accounts are held in the name of the Accra Technical University and not private individuals. Finally, respondents acknowledge that the University has organogram that defines lines of authority and responsibility.

The existence of several procedures assures that Accra Technical University's effort in the implementation of internal controls, as noted in [19], internal controls assist management and auditors to execute their duties. These internal controls are established by adopting policies and procedures with each system of control having specific function to perform. It is noted that the policies and procedures instituted cover a number of control areas and relevant in assisting management in the execution of their duties to give direction and motivation and provide vision towards attaining set organizational goals. It is important for these policies and procedures to exist to overcome loopholes in the administration system.

\subsubsection{Conditions in the Control Environment Affect Internal Controls Implementation}

Figure 5 below shows results for how conditions in the control environment affect the implementation of internal controls at Accra Technical University.

Results indicate that the tendency to override control procedures in order to get things done and compliance to generally accept accounting standards are high and pose challenge to the implementation of internal controls at the University.

Secondly, staff awareness and understanding of internal control mechanisms, ability of control procedures to slow down work and the independence of the internal auditor from management are low and pose minimum challenge.

The effect of all conditions are medium, the most prominent is the proper documentation and communication of internal control mechanism across the University.

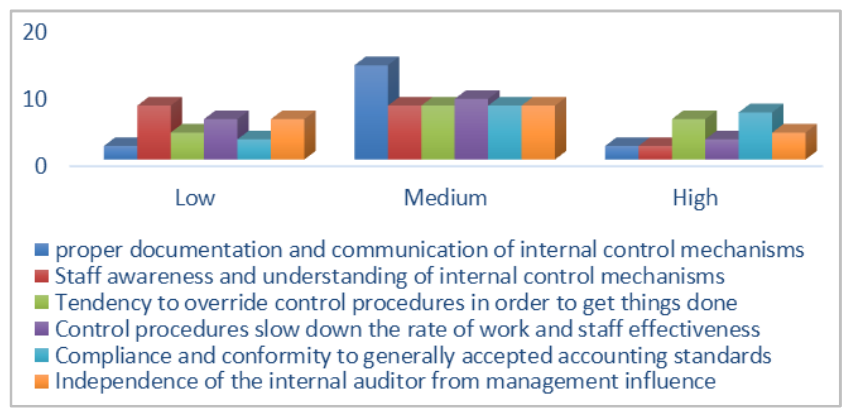

Figure 5. Conditions that affect implementation of internal controls at Accra Technical University.

\subsection{Main Findings}

The study set out to assess internal control systems at Accra Technical University investigating their existence and determining their implementation effectiveness. The main findings are:

Accra Technical University implements control systems that are aimed at conducting business in an orderly and efficient manner; ensuring accuracy and completeness of financial information; enforcing adherence to internal policies; preventing and detecting fraud and error as well as safeguarding assets of the university. This covers all objectives of internal controls operational, reporting and compliance.

Although the Technical University has instituted policies and procedures to govern the implementation of internal controls, staff awareness and understanding of such policies is limited and their evaluation and enforcement is abysmal. In effect, while appropriate documents may exist, staff are largely unaware and lack the relevant knowledge of what constitutes proper conduct and their associated violation 
penalties.

The Technical University exhibits high conformity to international standards and the present regulatory regime in the preparation of its financial reports and fiscal management. In addition to adherence to the regulations [12] it also ensures a religious use of the Financial Administration Regulation [14]; the Labour Act, in its Human Resource management; the Internal Audit Act to establish an independent Internal Audit Unit, and the Public Procurement Act for transparent, efficient and fair expenditure.

Conditions in the control environment affect the implementation of internal controls at the University. Whereas compliance to generally accepted accounting standards and the tendency of management to override procedures are high, staff awareness and understanding of policies, the independence of the internal auditor and tendency of procedures to slow work are low.

Overall, the implementation of internal control systems at Accra Technical University is judged to be "quite effective" comprising rules, policies and procedures that govern the university, provide better control and a way of engaging each employee/staff for better administration of their assigned activities or duties towards the attainment of set goals and objectives.

\section{Conclusion and Recommendations}

\subsection{Conclusion}

The relevance of internal controls in organizations have been duly recognized as a process for assuring achievement of set objectives in operational efficiency, reliable financial reporting and compliance with regulatory and international standards. Noting that internal controls are not merely policy manuals and forms, but effected by people, it is important to recognize that everyone has a role to play in the internal control systems implemented in an organization. Whiles managers and supervisors have the responsibility to ensure internal controls are established and functioning properly towards attaining set goals and objectives, it is imperative that each employee/staff is aware of and understands proper internal control procedures associated with their specific functions. The University as a public institution with its associated problems related to limited resources is entreated to implement effective internal controls for the judicious utilization, monitoring and management of business processes towards success and sustainability.

The study reveals that Accra Technical University (ATU) has instituted policies and procedures to enhance the implementation of internal controls. However, staff awareness regarding such policies and penalties for violation are low and should be improved. Although most of the departments are ahead in the effective implementation of internal controls, the following departments have been identified as having the weakest internal controls at the University:

Academic Affairs Department - ineffective admission processes resulting in poor admission choices leading to enrolment of unqualified students at times and lack of effective supervision and monitoring of Lecturers;

General Administration Department - weak supervision and enforcement of policies and procedures leading to lapses in the control procedures at the University;

Environment and Sanitation Department -inability to efficiently coordinate activities within the department due to lack of appropriate policies regarding the execution of duties and supervision;

Mechanical Department - operators of a Garage at the University, this department does not show consistency in operations leading to non-transparent processes, poor financial reporting and largely inefficient operations;

Furniture Department - operators of a commercial furniture workshop, they exhibit poor accounting practices and inaccurate financial information;

Overall, the weaknesses of controls systems at ATU are summed as follow: inability to enforce effective control policies and procedures; high level of staff unawareness of internal control systems; inadequate monitoring and evaluation of instituted internal controls; lack of monitoring, identification and assessment of financial reporting risk in an on-going basis throughout the University.

Generally, the implementation of internal controls at Accra Technical University is rated as "quite effective" but for the lapses enumerated above. It is imperative that to deliver on its mandate and meet set organizational goals and objectives, management takes steps to ensure that control environment and control procedures are effectively implemented with high employee/staff awareness and active participation towards success.

\subsection{Recommendations}

After assessing internal control systems at Accra Technical University, the study makes the following recommendations for improvement and successful implementation:

Improve staff awareness of policies regarding internal controls; what constitutes proper conduct and the associated penalties for violations. In effect, staff would be better equipped with information about internal controls pertaining to their assigned activities and understand the need to comply with such policies and procedures. Recognizing that internal control is effected by people and everyone in the organization has a role to play, it is important to ensure a university-wide shared value of internal controls to foster individual and collective efforts necessary for implementation success.

There is the need for continuous monitoring, identification and assessment of the internal control systems established and implemented to ensure they are functioning properly and meeting expectation. In so doing, any hitch in the implementation is quickly noted, reported and rectified appropriately before it escalates.

Errors must be corrected promptly. However, errors detected at any stage of a process should receive prompt corrective action and be reported to the appropriate level of management.

It is evident some departments are weak in internal controls due to the lack of requisite operational procedures and 
manuals. The University should endeavor to establish and implement tailored operational policies and procedures for the different facets or functional units accordingly. These policies and procedures should be enforced as well.

When a significant process or transaction is performed within a department, there should always be another level of review and approval performed by an individual independent of the process. The reviewer should have the experience and knowledge to be able to identify errors and omissions. The approval should be documented to verify that a review has been done.

\section{Acknowledgements}

We are thankful to our colleague Felix Kutsanedzie for providing scientific guidance and technical assistance towards this publication.

\section{References}

[1] Committee of Sponsoring Organisation (2011): Internal Control, Integrated Framework: http://www.coso.org/Publications/COSORelease_1.8.07 (2016, 15 January).

[2] Iddrisu, A. and Anang, F. (2010) Internal Financial Control Procedures in Second Cycle Institutions. Unpublished Dissertation pg. 8, 9-10.

[3] Business and Financial Times. General News of Wednesday, 21 November 2007" Mitigating Corporate fraud, abuse and waste the role of the internal auditor".

[4] Yin R. (2014). Case study research: design and methods. 5th ed. Sage, Los Angeles.

[5] Baxter, P. and Jack, S. (2008): Qualitative case study methodology: study design and implementation for novice researchers. The Qualitative Report, 13 (4), 544-559.
[6] Miles M. B. and Huberman A. M. (2003): Qualitative data analysis: A sourcebook of new Methods. Beverly Hills: Sage Publications

[7] Sullivan T. J. (2001). Method of social research, London: Harcourt College publishers.

[8] American Institute of Certified Public Accountants (1949).

[9] Corbetta, G. and Salvato C. (2004): Self-Serving or Self-Actualizing? Models of man and Agency costs in different types of family firms: A commentary on "comparing the agency costs of family and non-family firms: conceptual issues and exploratory evidence". Entrepreneurship Theory and Practice, 355-362.

[10] Albanese, R., Dacin, M. T. and Harris, I. C. 1997 Agents as Stewards. The Academy of Management Review, 22 (3): 609-611.

[11] Davis, J. H., Schoorman, F. D. and Donaldson, L. (1997). Toward a stewardship theory of management. Academy of Management review, 22 (1), 20-47.

[12] COSO (2013) Framework and SOS Compliance. Association of Accountants and Financial Professions in Business.

[13] Financial Administration Regulation (2004) (L. I. 1802), Ghana.

[14] Financial Administration ACT 2003, ACT 654. Ghana.

[15] The Labour Act 2003, Ghana Part III Section 8 to 15.

[16] Internal Audit Agency Act, 2003 (Act 658) Ghana.

[17] Audit Service Act 2000 (Act 584) Ghana.

[18] Public Procurement Act, 2003 (Act 663) Ghana.

[19] Kwasi, C. C. P. \& Lokko, G. W. (2013). Evaluate the significance of Internal Control System in the Rural Banking Sector International Conference on Technology and Business Management, March 2013, All Nations University, Ghana. 